\title{
Visits to figurative art museums may lower blood pressure and stress
}

\section{Stefano Mastandrea, Fridanna Maricchiolo, Giuseppe Carrus, Ilaria Giovannelli, Valentina Giuliani \& Daniele Berardi}

To cite this article: Stefano Mastandrea, Fridanna Maricchiolo, Giuseppe Carrus, Ilaria Giovannelli, Valentina Giuliani \& Daniele Berardi (2018): Visits to figurative art museums may lower blood pressure and stress, Arts \& Health, DOI: 10.1080/17533015.2018.1443953

To link to this article: https://doi.org/10.1080/17533015.2018.1443953

曲 Published online: 05 Mar 2018.

Submit your article to this journal $\sqsubset \pi$

Џ Article views: 4

Q View related articles ¿

View Crossmark data ¿ 


\title{
Visits to figurative art museums may lower blood pressure and stress
}

\author{
Stefano Mastandrea ${ }^{a}$, Fridanna Maricchioloa , Giuseppe Carrus ${ }^{a}$ iD, Ilaria Giovannellia, \\ Valentina Giuliania and Daniele Berardi ${ }^{b}$

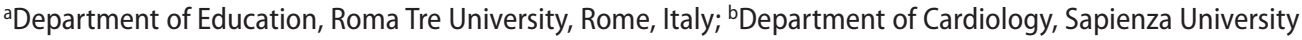 \\ of Rome, Rome, Italy
}

\begin{abstract}
Background: The research aimed to assess, through physiological measurements such as blood pressure and heart rate, whether exposure to art museums and to different art styles (figurative vs. modern art) was able to enhance visitors' well-being in terms of relaxing and stress reduction.

Method: Participants $(n=77)$ were randomly assigned to one of three conditions, on the basis of the typology of the art style they were exposed to in the museum visit: (1) figurative art, (2) modern art and (3) museum office (as a control condition). Blood pressure and heart rate were measured before and after the visits.

Results: Diastolic values of the participants were quite stable, as expected in people who do not suffer hypertension; we therefore considered only variations in systolic blood pressure. The majority of the participants exposed to figurative art significantly decreased systolic blood pressure compared to those exposed to modern art and museum office. No differences were found in the heart rate before and after the visit for the three groups.

Conclusion: Findings suggest that museum visits can have health benefits, and figurative art may decrease systolic blood pressure.
\end{abstract}

\section{ARTICLE HISTORY}

Received 9 November 2017 Accepted 20 February 2018

\section{KEYWORDS}

Restorativeness; art museum; figurative and modern art styles; psycho-physiological measures; blood pressure

\section{Introduction}

Several studies have addressed the topic of the restorative potential of natural and built environments, and the related health benefits of experiences in nature (Hartig \& Staats, 2006; Kaplan, 1995; Kaplan \& Kaplan, 1989). These findings have suggested that the experience of nature lowers stress and mental fatigue more than with built environment (Berman, Jonides, \& Kaplan, 2008; Hartig, Evans, Jamner, Davis, \& Gärling, 2003; Ulrich et al., 1991). A few studies have tested the restorative effects of actual and represented natural elements inside built settings. It was found that mural paintings (e.g. Felsten, 2009) and simulated natural scenes, viewed in indoor settings (e.g. De Kort, Meijnders, Sponselee, \& ljsselsteijn, 2006), have restorative effects. 
"Built environment" is, however, a broad category; often it refers to aesthetically unpleasant, urban environments. A city, for example, is mainly a built environment with some insertions of green spaces. Recently, several studies focused attention on green spaces inside built settings, and their ability to promote restoration. The results suggested that small green areas in the city can aid people's restoration: a park, a garden in a house or in a school or even a balcony in an apartment all have some restorative power (Carrus et al., 2017; Carrus, Passiatore, Pirchio, \& Scopelliti, 2015; Van den Berg, Hartig, \& Staats, 2007). Referring to the huge corpus of theories and empirical findings on restorative environments (Hartig, 2004), in this paper, we move further along this line of investigation, and aim at studying whether a totally built and artificial environment, such as an art museum, can have a restorative potential and promote human health and well-being.

\section{Art museums as restorative environments}

Art museums are very interesting built settings that attract many people for their variety in terms of the collections held. Generally, everything in a museum is artificial, from the halls to the artworks, from the light to the furniture, typically with no nature at all except for the landscape represented in the paintings (and even this is "artificial").

There are good reasons to argue that art museums should be conceived as potentially restorative environments. Some studies have suggested that participation in cultural events promotes well-being (Napier et al., 2014). Such observations led several museums and art galleries to organize services assessing the health effects of visits (Chatterjee \& Camic, 2015). As Chatterjee and Noble (2013) suggested, there are not many studies referring to the efficacy of museums enhancing human health and well-being. Using standardized physiological measures (heart rate, skin conductance, etc.) may be a good strategy to assess the visitor's aesthetic experience in an art museum, as they could help, more than self-reports, to control for the subjective variability linked to individual preferences or cultural differences in the appreciation of museum experiences (Brieber, Leder, \& Nadal, 2015; Tschacher et al., 2011). Clow and Fredhoi (2006) aimed to study possible stress reduction of a group of visitors to the Guildhall Art Gallery, London. Participants answered a short questionnaire and provided a saliva sampling measure on arrival at the gallery. The measures were repeated 40 min later, after the completion of the visit. Self-reported stress decreased after the visit, from 5.1 to 2.1 (out of 10); the cortisol levels from the saliva sampling also decreased from 5.8 out to 3.9 (out of 10).

In this paper, we examine the effects of different art styles (figurative vs. modern) on visitors' health and well-being. Previous studies have reported a difference between the two art styles in several psychological indicators. Modern art museum visitors were found to have higher scores on the Zuckerman (1979) "sensation seeking" personality trait, compared to visitors to ancient art museum, who focused on cultural enrichment (Mastandrea, Bartoli, \& Bove, 2007, 2009). It may be that modern art visitors are challenged and aroused by their visit, whereas figurative art visitors are seeking a more contemplative experience. If so, it is plausible that the latter could yield lower stress levels than the former.

Heart rate and blood pressure are indicators of cardiovascular health. Stress raises heart rate and pressure measures (Mancia et al., 2013). Visits to art museum, in particular representational art style, may have positive effects on stress, decreasing heart rate and blood 
pressure. On the other hand, viewing challenging art (abstract and modern) may reverse the effect increasing the arousal.

Psychophysiological indicators can be considered implicit measures of the individual reaction to art stimuli. Previous studies have shown differences in the implicit evaluation of different art, architecture and design styles; classical stimuli were more appreciated than modern ones, but not in an explicit evaluation (Mastandrea, Bartoli, \& Carrus, 2011; Mastandrea \& Maricchiolo, 2014).

In the current study, we conducted a field experiment in an actual museum setting, to get closer to observing the genuine effect of the art experience in the participants, thus increasing the ecological validity of our study.

The research was conducted in the National Gallery of Modern Art in Rome, which hosts two collections, one of the nineteenth- and one of the twentieth-centuries, figurative and modern art, respectively. We compared the effects of the two art styles on measures of stress.

Our hypothesis was that the visit to the figurative art collection would lead to the largest decrease in blood pressure and heart rate. Figurative art visit should be more restorative than the modern art visit and the control condition because of the major comprehensibility and the activation of mainly positive emotions of this art style. Moreover, we hypothesized that, in line with previous studies, there should be no difference in the explicit evaluation of the two art styles.

\section{Method}

\section{Participants and setting}

Seventy-seven undergraduate students with no training in the arts volunteered for the study (female $=64$; mean age $=22.5$; SD $=5.2$ ). They received course credits for participation. Participants were naive about the purpose of the experiment.

Participants were randomly assigned to one of three conditions, according to the museum halls to be visited: 23 figurative art, 23 modern art and 21 control condition (visit to museum offices). According to the arrival order to the museum, the first participant was assigned to condition 1 (figurative), the second to condition 2 (modern) and the third to condition 3 (office), and so forth.

The halls containing figurative and modern art were separate. The figurative artworks depicted landscapes, portraits, architecture, etc.; the modern artworks consisted of abstract, expressionist and informal art paintings, three-dimensional geometrical sculptures and contemporary art installations. In the control condition, participants visited offices of the Gallery.

\section{Physiological measures}

To measure well-being, two physiological measures were collected: blood pressure (BP) and heart rate (HR). BP comprises two measures: systolic and diastolic. Both depend on the activity of the heart muscle that contracts (systole) and relaxes (diastole) between each heartbeat. Systolic blood pressure (SBP) can be used to discriminate a state of well-being from a disease (hypertension, high blood pressure) (Mancia et al., 2013); at the age of the participants, the SBP may detect emotional changes. BP and HR were measured using an 
automatic sphygmomanometer (Omron HEM-780, Automatic Blood Pressure Monitor) in a sitting position (the back against the back of a chair); for each participant, two BP measurements were taken, alternatively in both arms (right and left) with the second 2 min after the first. Typically, the second measure can register a reduction of the alarm level, usually associated with the first, and provides a better measurement (Myers et al., 2011). Differences in $\mathrm{BP}$ variations from pre- to post-test between the experimental groups were examined as an indication of differences in the emotional states due to the different treatments.

Together with BP, heart rate (HR) was also measured. HR, too, can signify physiological arousal (Parati et al., 2008). BP and HR were both measured at Time 1 and Time 2, before and after the visit to the art collections and offices of the museum.

In obtaining the physiological measurements, we followed the guidelines of the European Society of Hypertension and of the European Society of Cardiology (Mancia et al., 2013). ${ }^{1}$ Participants were asked to sign a written agreement showing they understood their blood pressure and heart rate would be measured.

According to the European Society of Hypertension and to the European Society of Cardiology (Mancia et al., 2013), for people suffering by hypertension, a difference in the changes of $8 \mathrm{~mm} \mathrm{Hg}$ in the SBP before and after a behavioural treatment (in our case, the art collection visit) can be considered an index of restorative, relaxing and well-being effect. We calculated the difference of variations of SBP in terms of $\mathrm{mmHg}$ before and after the visit for each participant in the three experimental conditions (Figurative, Modern and Control). A reduction of the SBP values would confirm our hypothesis of the restorative art effect. Based on these guidelines, three ranges of SBP change after the art visit were calculated: (1) a reduction of $8 \mathrm{~mm} \mathrm{Hg}$ of SBP or more (a restorative effect); (2) reduction between 0 and 7 (a stable effect); (3) an increase of SBP (a stress effect).

After the second physiological measure, we asked participant to state their "liking" of the visit, through a single-item self-report (on a 5 points scale), prior to a final debriefing.

\section{Procedure}

Participants were met out of the museum individually, in the morning (to avoid disturbing effects due to blood pressure variations related to different hours of the day). After welcoming, they were brought into the museum from the back door, to prevent them from seeing any artwork and museum halls before the experiment. Later, they were taken to a small, quiet and comfortable room inside the offices of the museum. The first phase of the study consisted of the measurement of blood pressure and heart rate. The second was the visit to the museum halls (or museum office for the control group). All visits lasted $5 \mathrm{~min}$. We decided to avoid a longer visit in order to minimize the likelihood of unwanted external interferences on the physiological measurements. After the visit, second BP and HR measurements were taken.

\section{Results}

Diastolic values of the participants were quite stable, as expected in people who do not suffer hypertension; we therefore considered only variations in systolic blood pressure. Out of the 23 participants in the figurative art visit, 13 (56.5\%) reduced their SBP, 7 (30.4\%) were stable and $3(13.1 \%)$ increased SBP. Out of the 23 participants in the modern art visit, 7 (30.4\%) 
reduced SBP, 10 (43.5\%) were stable and $6(26.1 \%)$ increased SBP. Out of the 21 participants in the control visit, 6 (28.6) reduced SBP, 6 (28.6\%) were stable and $9(42.8 \%)$ increased SBP.

If we consider the pre-post visit SBP variations across the three groups, findings showed a significant decrease in SBP after the visit only for the figurative art condition, from $116.2 \mathrm{~mm}$ $\mathrm{Hg}$ to $108.7(t(22)=3.09, p=.001)$. For the modern art and control groups, the decrease was non-significant, from 115.9 to $112.17(t(22)=1.656, p=.112)$ and from 119.8 to $114.9(t(20)$ $=1.521, p=.144)$, respectively (Figure 1 ).

The heart rate values decreased in the three conditions (figurative from 87.26 to 81.74 ; modern from 90.41 to 84.91 ; control from 86.43 to 81.48 ), with a significant main effect from pre to post tests $\left(F(1,63)=35.479, p<.001, \eta^{2}=.360\right)$, but no significant interaction (Figure 2 ).

For explicit judgements on liking, a significant difference among the three conditions was found $(F(2,64)=3.736, p=.029)$. Duncan post hoc analysis showed that the office visit liking mean score was significantly lower $(M=3.38$; $\mathrm{SD}=.86)$ than those of the figurative $(M=4.04 ; \mathrm{SD}=.76)$ and of the modern art visits $(M=3.91$; SD $=.9)$, for $p<.05$ (effect size were Cohen's $d=-.82$, and $=-.60$, respectively). Figurative and modern art visits were liked at almost the same level, with no statistically significant differences ( $p=.608$; Cohen's $d=.16$ ). No correlations between SBP values and aesthetic appreciation for the three groups were observed (Table 1).

\section{Discussion}

In this study, we investigated pre-post BP and HR of a non-clinical sample, with the aim to verify positive physiological impact of museum visit in three different conditions: figurative art, modern art and control condition (museum office). The main findings show that the majority of the participants in the figurative art condition had a SBP reduction after the visit, while only one-third of the modern art decreased SPB.

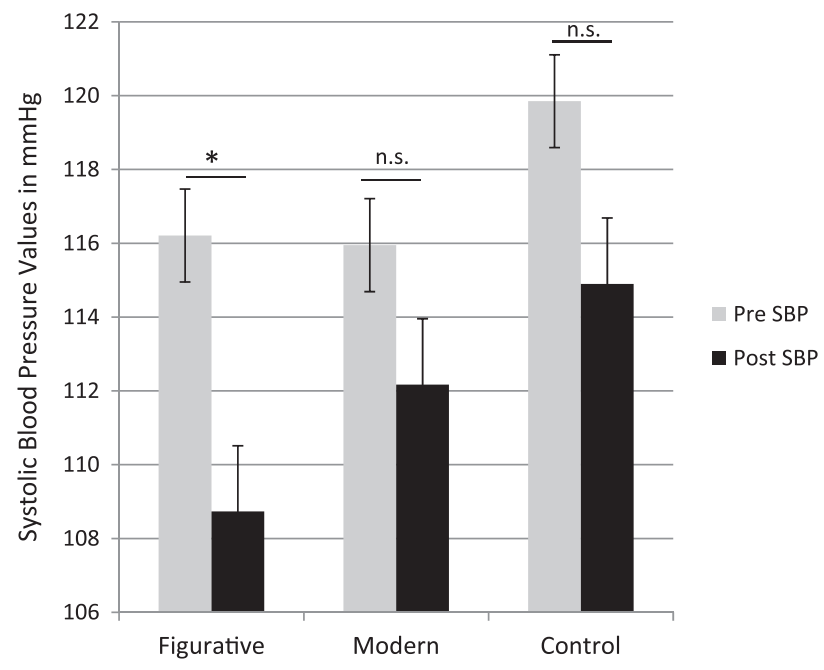

Figure 1. Averaged SBP values before and after the visit in the three experimental conditions. Note: Error bars represent standard errors of the mean $\left({ }^{*} p<.001\right)$. 


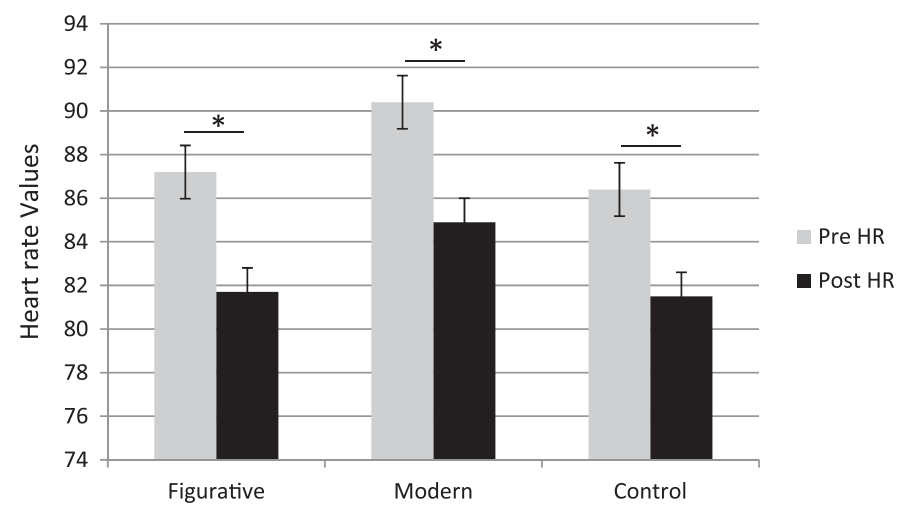

Figure 2. Averaged HR values before and after the visits in the three experimental conditions. Note: Error bars represent standard errors of the mean $\left({ }^{*} p<.001\right)$.

Table 1. Correlations between SBP values and liking for the three conditions.

\begin{tabular}{lccc}
\hline & Figurative art & Modern art & Control \\
\hline$r$ & .283 & .112 & .216 \\
$p$ & .190 & .611 & .346 \\
$N$ & 23 & 23 & 21 \\
\hline
\end{tabular}

Studies on figurative art and ancient art museums have reported positive feelings in participants (Smith \& Smith, 2001), but modern art can arouse negative emotions (Silvia \& Brown, 2007). However, modern art can also be highly stimulating and engage debate, social interaction, curiosity and discussion, all positive aspects of visiting art museums and viewing art. For example, in a study with people with dementia and caregivers, across traditional and contemporary galleries, it was found that both art sites promoted well-being benefits, including positive social impact and cognitive capacities enhancement (Camic, Tischler, \& Pearman, 2014). But regarding physiological measures, figurative art can have a positive effect on decreasing systolic blood pressure compared to modern art. In the current study, modern artwork viewed by participants at the National Gallery of Modern Art of Rome was found to be provocative and distressing for some viewers, but also interesting, despite the negative aspects, and very much appreciated. This may help to explain our finding that only figurative art lead to a decrease in SBP. Indeed, along the same lines as what Silvia \& Brown (2007) reported, twice as many participants in the current study who were assigned to the modern art condition increased their SBP values after the visit. Visiting an unattractive place such as museum offices may be even worse (e.g. tedious or even frustrating), especially knowing that the museum collections are there, just a few steps ahead, but out of reach. The findings on heart rate scores are less clear, as values decreased after the visit to a similar extent in all the three conditions; it might be that just being in a museum, even in an office, could be sufficient to lower the heart rate.

Another interesting point is the difference between the automatic physiological reaction and the explicit liking evaluation of the visit. Participants liked the two art styles equally well, and it is noted that the reduction in SBP was not correlated with liking. Therefore, reduction of the SBP might not be attributed to differences in the explicit appreciation of the two kinds of art. We can evaluate how much we like the art visit using deliberate processes, such as 
thinking about the experience just done, but we cannot control the physiological body reaction. However, this finding might slightly contrast with previous studies showing that observers generally prefer figurative over abstract art in laboratory studies (Boselie \& Cesaro, 1994; Feist \& Brady, 2004; Heinrichs \& Cupchik, 1985; Kettlewell, Lipscomb, Evans, \& Rosston, 1990), or classic buildings over contemporary ones (Mastandrea et al., 2011; Stamps \& Nasar, 1997; Whitfield, 1983). The apparent incongruence of the findings in the current research (same level of liking of both art styles) vs. previous researches (preference for figurative art) might be due to the settings where the experiments were conducted: viewing art in a real setting like a museum is quite different that viewing art in a computer screen in a laboratory. Locher, Smith, and Smith (1999) compared participants evaluation of painting viewed in the original vs. reproduction formats; they found that it was the original artworks in the museum that was something unique and more valuable than the reproduction. In what he called "the museum effect," Smith (2014) proposed a model that describes the many factors that lead visitors to the appreciation of a piece of art during an art museum experience. The fact that we did not find any differences between the explicit appreciation of the two art styles (figurative vs. modern) could be due to the effect played by the museum: the same level of appreciation of the artworks of different styles could be caused by the overall aesthetic experience that can take place in a real museum setting.

The current findings are also in line with previous studies on the implicit evaluation of different styles in visual art, architecture and design, assessed through implicit cognition measures, such as the Implicit Association Test (e.g. Chirumbolo, Brizi, Mastandrea, \& Mannetti, 2014; Mastandrea \& Maricchiolo, 2014; Mastandrea et al., 2011). These previous studies showed a strong implicit preference for figurative art, classical architecture and traditional design objects, but no differences on self-report (i.e. Likert scales) judgements of the styles (figurative-abstract art, classical-contemporary architecture and traditional-modern design objects). We might thus speculate that a first step of the art evaluation process might be implicit, followed by the proposition-based explicit reasoning that has the aim to deeply process the outcome of the automatic processes.

\section{Limitations}

A limit of our study might be the small sample size; thus, future replications with larger samples are needed to have more statistical power. Furthermore, it must be underlined that whilst the differences in BP and HR have some statistical significance, they are not clinically significant because the sample was composed by a not clinical population. Therefore, a case needs to be made as to the relevance of collecting this type of data also with a clinical population.

The use of continuous blood pressure measurements and heart rate variability could also help in shedding more light on the mechanisms linked to BP and HR variations when looking at different art styles.

\section{Conclusions and implications}

Taken together, our findings suggest that museum visits can have health benefits, and figurative art may decrease Systolic Blood Pressure. An important issue of the present research is that participants did not choose spontaneously to visit the museum. This non-deliberate 
way of visiting the museum might strengthen the results we obtained. If bringing people to museums and showing them a realistic art style can have a positive effect on physiological reaction such as blood pressure, we might consider an art-prescription to support medical therapies of patients with hearth-related diseases. This sort of "behavioral treatment" could be indicated for people who suffer from hypertension or other health problems, gaining direct beneficial effects in terms of relaxation and stress recovering.

\section{Note}

1. Participants had to meet the following requirements: they must not be suffering of cardiovascular diseases (such as neurodegenerative disorders, etc.) and of arterial hypertension; they must not take any anti-hypertensive drug therapy. Other criteria to meet is that they should not use drugs and do not have to play sport at a competitive level since at least the last six months; moreover, no caffeine and smoking in the hour preceding the survey data; the women should not be pregnant or menstruating. Participants signed a statement that they met these criteria.

\section{Acknowledgements}

We would like to thank the Director (Maria Vittoria Marini Clarelli) and the staff of the National Gallery of Modern Art of Rome, who enabled us to carry out the research in the museum. We thank the two reviewers for their most valuable comments on the manuscript.

\section{Disclosure statement}

No potential conflict of interest was reported by the authors.

\section{Funding}

This work was supported by Department of Education, Roma Tre University [grant number 814000].

\section{ORCID}

Giuseppe Carrus (D) http://orcid.org/0000-0003-1680-1657

\section{References}

Berman, M. G., Jonides, J., \& Kaplan, S. (2008). The cognitive benefits of interacting with nature. Psychological Science, 19, 1207-1212. doi:10.1111/j.1467-9280.2008.02225.x

Boselie, F., \& Cesaro, A. (1994). Disjunctive ambiguity as a determinant of the aesthetic attractivity of visual patterns. Empirical Studies of the Arts, 12, 85-94.

Brieber, D., Leder, H., \& Nadal, M. (2015). The experience of art in museums: An attempt to dissociate the role of physical context and genuineness. Empirical Studies of the Arts, 33, 95-105. doi:10.1177/0276237415570000

Camic, P. M., Tischler, V., \& Pearman, C. H. (2014). Viewing and making art together: A multi-session art- gallery-based intervention for people with dementia and their carers. Aging \& Mental Health, 18, 161-168. doi:10.1080/13607863.2013.818101

Carrus, G., Passiatore, Y., Pirchio, S., \& Scopelliti, M. (2015). El contacto con la naturaleza en los contextos educativos podría mejorar el funcionamiento cognitivo y fomentar el comportamiento social positivo [Contact with nature in educational settings might help cognitive functioning and promote positive social behaviour]. Psyecology, 6, 191-212. doi:10.1080/21711976.2015.1026079 
Carrus, G., Scopelliti, M., Panno, A., Lafortezza, R., Colangelo, G., Pirchio, S., ... Sanesi, G. (2017). A different way to stay in touch with 'urban nature': The perceived restorative qualities of botanical gardens. Frontiers in Psychology, 8, 1-9. doi: 10.3389/fpsyg.2017.00914

Chatterjee, H. E., \& Camic, P. M. (2015). Special issue on Museums, culture and wellbeing. Editorial: The health and wellbeing potential of museums and art galleries. Arts \& Health: An International Journal for Research, Policy and Practice, 8, 183-186. doi:10.1080/17533015.2014.941144

Chatterjee, H. J., \& Noble, G. (2013). Museums, health and well-being. Farnham, Surrey: Ashgate Publications.

Chirumbolo, A., Brizi, A., Mastandrea, S., \& Mannetti, L. (2014). Beauty is no quality in things themselves: Epistemic motivation affects implicit preferences for art. PLOS ONE, 9, e110323. doi:10.1371/journal. pone. 0110323

Clow, A., \& Fredhoi, C. (2006). Normalisation of salivary cortisol levels and self-report stress by a brief lunchtime visit to an art gallery by London City workers. Journal of Holistic Healthcare, 3, 29-32.

De Kort, Y. A. W., Meijnders, A. L., Sponselee, A. A. G., \& ljsselsteijn, W. A. (2006). What's wrong with virtual trees? Restoring from stress in a mediated environment. Journal of Environmental Psychology, 26, 309-320. doi:10.1016/j.jenvp.2006.09.001

Feist, G. J., \& Brady, T. R. (2004). Openness to experience, nonconformity, and the preference for abstract art. Empirical Studies of the Arts, 22, 77-89.

Felsten, G. (2009). Where to take a study break on the college campus: An attention restoration theory perspective. Journal of Environmental Psychology, 29, 160-167. doi:10.1016/j.jenvp.2008.11.006

Hartig, T. (2004). Restorative environments. In C. Spielberger (Ed.), Encyclopedia of applied psychology (Vol. 3, pp. 273-279). San Diego, CA: Academic Press.

Hartig, T., Evans, G. W., Jamner, L. D., Davis, D. S., \& Gärling, T. (2003). Tracking restoration in natural and urban field settings. Journal of Environmental Psychology, 23, 109-123. doi:10.1016/S02724944(02)00109-3

Hartig, T., \& Staats, H. (2006). The need for psychological restoration as a determinant of environmental preferences. Journal of Environmental Psychology, 26, 215-226. doi:10.1016/j.jenvp.2006.07.007

Heinrichs, R. W., \& Cupchik, G. C. (1985). Individual differences as predictors of preference in visual art. Journal of Personality, 53, 502-515.

Kaplan, S. (1995). The restorative benefits of nature: Towards an integrative framework. Journal of Environmental Psychology, 15, 169-182. doi:10.1016/0272-4944(95)90001-2

Kaplan, S., \& Kaplan, R. (1989). The experience of nature: A psychological perspective. New York, NY: Cambridge University Press.

Kettlewell, N., Lipscomb, S., Evans, L., \& Rosston, K. (1990). The effect of subject matter and degree of realism on aesthetic preferences for paintings. Empirical Studies of the Arts, 8, 85-93. doi:10.2190/ Y8JA-3GUR-M08C-BPEC

Locher, P. J., Smith, L., \& Smith, J. (1999). Original paintings versus slide and computer reproductions: A comparison of viewer responses. Empirical Studies of the Arts, 17, 121-129. doi:10.2190/R1WNTAF2-376D-EFUH

Mancia, G., Fagard, R., Narkiewicz, K., Redon, J., Zanchetti, A., Böhm, M., ... Galderisi, M. (2013). 2013 ESH/ ESC Guidelines for the management of arterial hypertension: The task force for the management of arterial hypertension of the European Society of Hypertension (ESH) and of the European Society of Cardiology (ESC). Blood pressure, 22, 193-278. doi:10.3109/08037051.2013.812549

Mastandrea, S., Bartoli, G., \& Bove, G. (2007). Learning through ancient art and experiencing emotions with contemporary art: Comparing visits in two different museums. Empirical Studies of the Arts, 25, 173-191. doi:10.2190/R784-4504-37M3-2370

Mastandrea, S., Bartoli, G., \& Bove, G. (2009). Preferences for ancient and modern art museums: Visitor experiences and personality characteristics. Psychology of Aesthetic, Creativity, and the Arts, 3, 164173. doi:10.1037/a0013142

Mastandrea, S., Bartoli, G., \& Carrus, G. (2011). The automatic aesthetic evaluation of different art and architectural styles. Psychology of Aesthetic, Creativity, and the Arts, 5, 126-134. doi:10.1037/a0021126

Mastandrea, S., \& Maricchiolo, F. (2014). Implicit and explicit aesthetic evaluation of design objects. Art \& Perception, 1-2, 141-162. doi:10.1163/22134913-00002015 
Myers, M. G., Godwin, M., Dawes, M., Kiss, A., Tobe, S. W., Grant, F. C., \& Kaczorowski, J. (2011). Conventional versus automated measurement of blood pressure in primary care patients with systolic hypertension: Randomised parallel design controlled trial. BMJ, 342, d286. doi:10.1136/ bmj.d286

Napier, A. D., Ancarno, C., Butler, B., Calabrese, J., Chater, A., Chatterjee, H., \& Woolf, K. (2014). Culture and health. The Lancet, 384, 1607-1639. doi:10.1016/S0140-6736(14)61603-2

Parati, G., Omboni, S., Palatini, P., Rizzoni, D., Bilo, G., Valentini, M., ... Mancia, G. (2008). Linee Guida della Società Italiana dell'Ipertensione Arteriosa sulla misurazione convenzionale e automatica della pressione arteriosa nello studio medico, a domicilio e nelle 24 ore [Guidelines of the Italian Society of Arterial Hypertension on the conventional and automatic measurement of blood pressure in the medical office, at home and in the 24 hours]. Ipertensione e Prevenzione Cardiovascolare, 15, 63-115.

Silvia, P. J., \& Brown, E. M. (2007). Anger, disgust, and the negative aesthetic emotions: Expanding an appraisal model of aesthetic experience. Psychology of Aesthetics, Creativity, and the Arts, 1, 100-106.

Smith, J. K. (2014). The museum effect: How museums, libraries, and cultural institutions educate and civilize society. Lanham, MD: Rowman \& Littlefield Publishers.

Smith, J. K., \& Smith, L. F. (2001). Spending time on art. Empirical Studies of the Arts., 19, 229-236. doi:10.2190/5MQM-59JH-X21R-JN5J

Stamps, A. E., \& Nasar, J. L. (1997). Design review and public preferences: Effects of geographical location, public consensus, sensation seeking and architectural styles. Journal of Environmental Psychology, $17,11-32$.

Tschacher, W., Greenwood, S., Volker, K., Wintzerith, S., van den Berg, K., \& Tröndle, M. (2011). Physiological correlates of aesthetic perception of artworks in a museum. Psychology of Aesthetics, Creativity, and the Arts, 6, 96-103. doi:10.1037/a0023845

Ulrich, R. S., Simons, R., Losito, B. D., Fiorito, E., Miles, M. A., \& Zelson, M. (1991). Stress recovery during exposure to natural and urban environments. Journal of Environmental Psychology, 11, 201-230. doi:10.1016/S0272-4944(05)80184-7

Van den Berg, A. E., Hartig, T., \& Staats, H. (2007). Preference for nature in urbanized societies: Stress, restoration, and the pursuit of sustainability. Journal of Social Issues, 63, 79-96. doi:10.1111/j.15404560.2007.00497.x

Whitfield, T. W. A. (1983). Predicting preference for familiar, everyday objects: An experimental confrontation between two theories of aesthetic behaviour. Journal of Environmental Psychology, 3(3), 221-237.

Zuckerman, M. (1979). Sensation seeking: Beyond the optimal level of arousal. Hillsdale, NJ: Erlbaum. 